\title{
Снижение нагрузки на окружающую среду за счет вовлечения техногенных отходов в получение теплоизоляционных материалов
}

\section{Манакова Н.К., Суворова О.В.}

Институт химии и технологии редких элементов и минерального сырья им. И.В. Тананаева КНЦ РАН, Anamumbl,manakova@chemy.kolasc.net.ru; suvorova@chemy.kolasc.net.ru

Аннотация. Проведены исследования по получению вспененных материалов теплоизоляционного назначения на основе кремнеземсодержащих техногенных отходов. В результате изучения взаимосвязей состава шихты, технологических режимов и свойств готовых изделий установлены оптимальное содержание компонентов в шихте и условия их получения. Показано, что использование модифицирующих добавок в виде золосо-

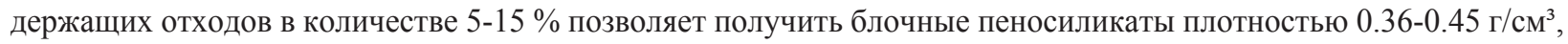
достаточно высокой прочностью 2.8-5.2 МПа и более низким по сравнению с материалами, полученными без использования модифицирующих добавок, водопоглощением 14-22 \%, теплопроводностью 0.09-0.107 Вт/м·К.

Ключевые слова: техногенные отходы, микрокремнезем, модифицирующие добавки, апатитонефелиновые отходы, зола, золошлаковая смесь, теплоизоляционный материал, пеностекольный материал.

\section{Reducing the impact on the environment through the involvement of industrial waste in obtaining heat-insulating materials}

\author{
Manakova N.K., Suvorova O.V. \\ Institute of chemistry and technology of rare elements and mineral raw materials I.V. Tananaeva KSC RAS, \\ Apatity,Russia,manakova@chemy.kolasc.net.ru; suvorova@chemy.kolasc.net.ru
}

\begin{abstract}
Studies have been carried out to obtain foam materials for thermal insulation purposes on the basis of silica-containing man-made waste. As a result of studying interrelations of the charge composition, process conditions and properties of final products, the optimum content of components in the mixture and the conditions for their receipt have been defined. It is shown that adding ash-containing waste to the charge in an amount of 5-15\% allows to obtain block foams with a density of $0.36-0.45 \mathrm{~g} / \mathrm{cm}^{3}$, a sufficiently high strength of 2.8-5.2 MPa and lowering in comparison with materials obtained without the use of modifying additives, water absorption of $14-22 \%$, thermal conductivity $0.09-0.107 \mathrm{BT} / \mathrm{M} \cdot \mathrm{K}$.
\end{abstract}

Keywords: technogenic waste, microsilica, modifying additives, apatite-nepheline waste, ash, ash-slag mixture, thermal insulation material, foam glass material.

Существенные объемы хвостов обогащения и отработанных горных пород, помещенных в отвалы, создают серьезный экологический и экономический ущерб в горнопромышленных районах и на прилегающих к ним территориях. Наиболее негативные последствия складирования техногенных отходов наблюдаются в регионах с экстремальными климатическими условиями, например, таких как Кольский полуостров. Разработка технологий переработки отходов в теплоизоляционные строительные материалы позволит отчасти облегчить нагрузку на окружающую среду, а также снизить себестоимость готовых строительных изделий.

В современной строительной отрасли все большую значимость приобретают материалы, обладающие теплоизолирующими свойствами и способные эффективно выполнять свои функции по сбережению энергетических ресурсов. Всему комплексу требований к высокоэффективным теплоизоляционным материалам по своим эксплуатационным показателям удовлетворяют вспененные стекловидные материалы. В настоящей действительности актуальной технологической и экономической проблемой является получение теплоизоляционных строительных материалов, характеризующихся улучшенными техническими характеристиками. В частности, материалы должны обладать одновременным сочетанием конструкционных и эксплуатационных свойств: высокой прочностью при малой плотности, низкой и стабильной теплопроводностью, долговечностью, химической и биологической устойчивостью, пожаробезопасностью. 
Проблеме вовлечения техногенных отходов, в том числе кремнеземсодержащих, в производство этих материалов и разработке технологий, исключающих дорогостоящий процесс варки исходного стекла уделяется повышенное внимание в последние годы (Мелконян и др., 2016, 2018, Суворова, Манакова, 2017, Манакова, Суворова, 2015, 2017, Кутугин и др. 2016). Это связано, прежде всего, с удорожанием традиционного исходного сырья, а также с энергозатратами на его добычу и переработку.

Ранее был разработан гранулированный вспененный материал на основе микрокремнезема, апатито-нефелиновых отходов и золошлаковой смеси. Получение материала основано на способности микрокремнезема взаимодействовать с щелочными компонентами с образованием полисиликатов. Источником порообразующего газа в этом случае является гидратированная поверхность силикатных частиц, которая формируется при увлажнении мелкодисперсной пробы водным раствором щелочи. Коэффициент теплопроводности полученного материала 0.075-0.08 Вт/м·К, плотность

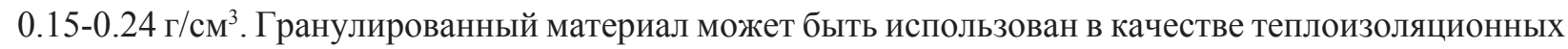
засыпок, утеплителя чердачных перекрытий, стен, кровли (Манакова, Суворова, 2012).

На основе анализа литературных данных и собственных исследований в рамках изучения низкотемпературного синтеза стеклофазы установлена возможность получения блочных вспененных материалов из кремнеземсодержащего сырья (Манакова, Суворова 2015). Полученные блочные материалы характеризовались низкой плотностью, стабильной теплопроводностью при наличии высокопористой структуры. Однако у таких пеносиликатов наблюдается повышенное водопоглощение, которое ограничивает их области применения.

Известно, что активное действие на макро- и микроструктуру теплоизоляционного материала оказывают модифицирующие добавки, правильный выбор и количество которых может привести к улучшению физико-механических показателей вспененного изделия. Успешно используются при получении различных строительных материалов золошлаковые отходы (Смолий и др., 2017, Яценко и др., 2015, Манакова, Суворова, 2012, Дамдинова и др., 2016). Добавление золы-уноса и золошлаковой смеси приводит к снижению показателя водопоглощения, а также увеличению морозостойкости теплоизоляционного материала. Кроме того, добавка золошлаковой смеси или золы-уноса способствует образованию большого количества замкнутых пор с более прочной межпоровой перегородкой, что также приводит к упрочнению материала. Расход модифицирующих добавок назначается в зависимости от требуемых параметров эксплуатационных характеристик вспененных теплоизоляционных материалов.

В качестве исходных сырьевых материалов использовались: кремнеземсодержащий продукт (микрокремнезем), полученный при переработке эвдиалитовых руд Ловозерского месторождения; отходы обогащения апатито-нефелиновых руд Хибинских месторождений; золошлаковая смесь и зола-унос Апатитской ТЭЦ.

Химический состав используемого сырья материалов представлен в таблице.

Таблица. Химический состав исходного сырья.

Table. Chemical composition of raw materials.

\begin{tabular}{|c|c|c|c|c|c|c|c|c|c|c|c|c|}
\hline & \multicolumn{10}{|c|}{ Содержание оксидов, мас. \% } \\
\cline { 2 - 13 } & $\mathrm{SiO}_{2}$ & $\mathrm{TiO}_{2}$ & $\mathrm{Al}_{2} \mathrm{O}_{3}$ & $\mathrm{Fe}_{2} \mathrm{O}_{3}$ & $\mathrm{CaO}$ & $\mathrm{MgO}$ & $\mathrm{P}_{2} \mathrm{O}_{5}$ & $\mathrm{Na}_{2} \mathrm{O}$ & $\mathrm{K}_{2} \mathrm{O}$ & $\mathrm{ZrO}_{2}$ & $\mathrm{CO}_{2}$ & $\mathrm{SO}_{3}$ \\
\hline Мкр. & 74.70 & 0.84 & 0.50 & 3.07 & 0.80 & 0.08 & 0.05 & 2.53 & 0.46 & 4.49 & - & - \\
\hline $\mathrm{AHO}$ & 35.98 & 4.43 & 16.60 & 12.22 & 9.13 & 1.25 & 4.11 & 10.77 & 4.59 & - & - & 0.15 \\
\hline ЗШС & 53.44 & 1.23 & 18.45 & 13.74 & 2.47 & 2.43 & 0.18 & 2.79 & 1.55 & 3.73 & 3.11 & 0.25 \\
\hline Зола-унос & 53.70 & 0.99 & 18.72 & 9.61 & 4.15 & 2.26 & $<0.01$ & 1.44 & 21.75 & - & 3.07 & 0.32 \\
\hline
\end{tabular}

Примечание. Мкр. - кремнеземсодержащий продукт переработки эвдиалитовых руд, АНО - апатито-нефелиновые отходы, ЗШС - золошлаковая смесь.

При получении блочных вспененных материалов использовали шихту состава, мас. \%: микрокремнезем 68-80, гидроксид натрия (в пересчете на $\mathrm{Na}_{2} \mathrm{O}$ ) 17-20, апатито-нефелиновые отходы 15. 


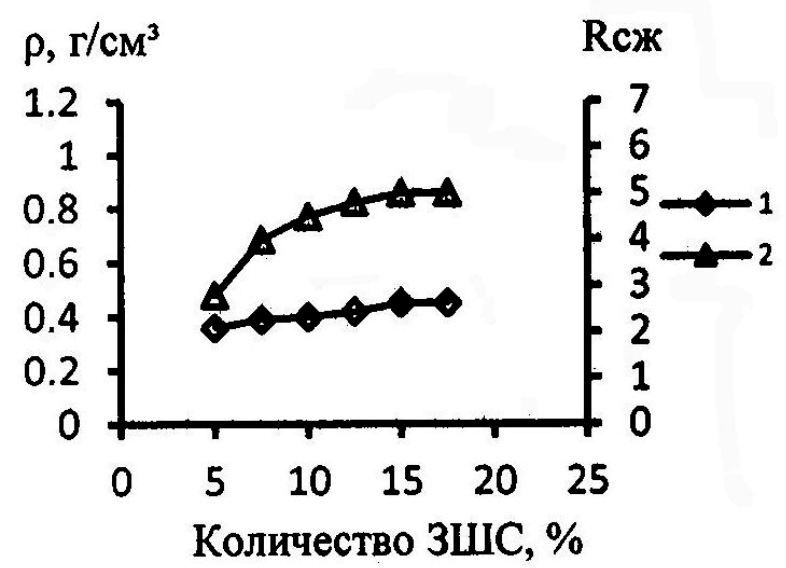

Рис. 1. Зависимость плотности (1) и прочности (2, МПа) от количества добавки золошлаковой смеси.

Fig. 1. Dependence of density (1) and strength (2, MPa) on the amount of ash-slag mixture additive.

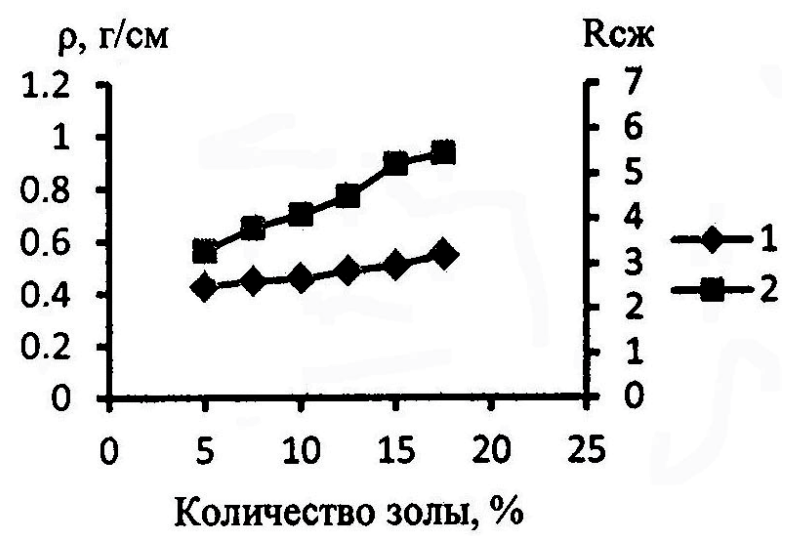

Рис. 3. Зависимость плотности (1) и прочности (МПа) от количества золы-уноса (2).

Fig. 3 Dependence of density (1) and strength (MPa) on the amount of fly ash (2).

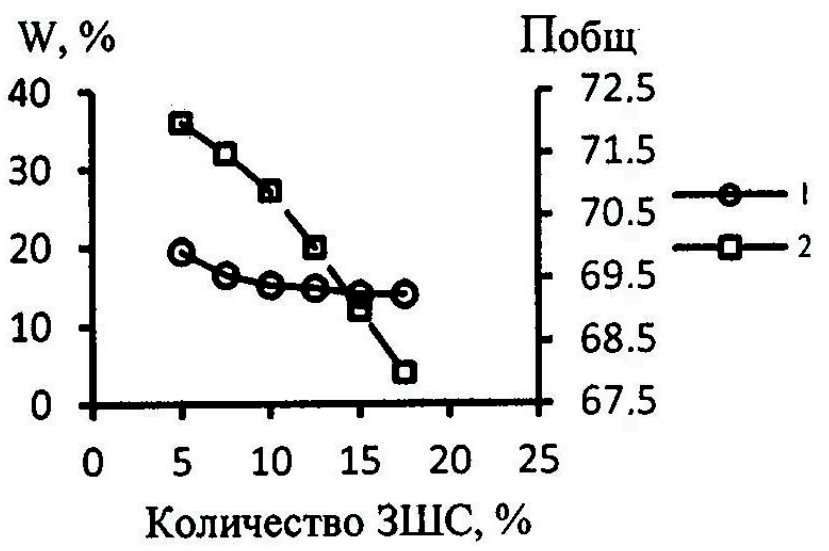

Рис. 2. Зависимость водопоглощения (1) общей пористости (2) от количества добавки золошлаковой смеси.

Fig. 2. Dependence of water absorption (1) and total porosity (2) on the amount of ash-slag mixture additive.

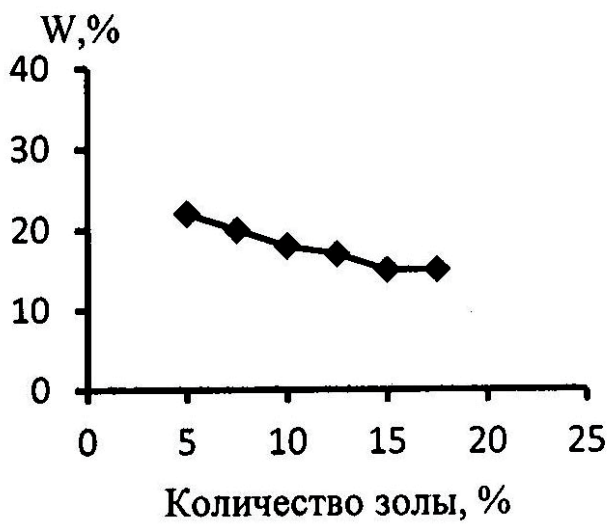

Рис. 4. Зависимость водопоглощения от количества золы-уноса.

Fig. 4. Dependence of water absorption on quantity fly ash.

Для улучшения характеристик изделий добавляли золошлаковую смесь и золу-унос в количестве от 5 до 17.5 \% (сверх 100). Пеносиликатные материалы получали по методике, приведенной в работе (Манакова, Суворова, 2017).

Для выявления оптимального состава, технологических параметров и получения качественных блочных пеносиликатов проводились исследования влияния добавки золы и золошлаковой смеси на технические свойства пеносиликатов. Некоторые результаты исследований представлены на рисунках 1-4. Данные приведены для образцов, вспененных при температуре $650^{\circ} \mathrm{C}$.

Как видно из представленных данных, использование модифицирующих добавок в виде золы или золошлаковой смеси в количестве 5-15 \% позволяет получить блочные пеносиликаты плотно-

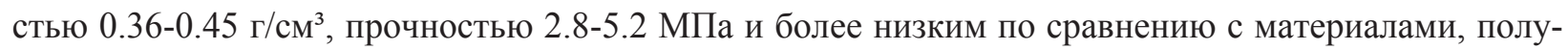
ченными без использования модифицирующих добавок, водопоглощением 14-22 \%. Теплопроводность этих материалов 0.09-0.107 Вт/м·К.

Инфракрасные спектры поглощения кристаллических силикатов характеризуются набором узких полос поглощения с определенными частотами колебаний. Вещества в стеклообразном состоянии дают огибающий спектр с сохранением тех же частот спектра. Анализ ИКС спектров полученных при оптимальных условиях пеносиликатов показывает наличие стеклофазы в образцах, что сви- 
детельствует о начале стеклообразования уже при относительно низкой температуре $650{ }^{\circ} \mathrm{C}$ (рис. 5). Эти данные сопоставимы с исследованиями Кетова П.А. (Кетов, 2012), проводимыми им при получении строительных материалов из гидратированных полисиликатов. Он отметил стеклообразование в системе микрокремнезем - гидроксид натрия при температурах $600-750^{\circ} \mathrm{C}$.

Таким образом, проведенные исследования показали эффективность использования техногенных кремнеземсодержащих отходов для получения гранулированных и блочных пеноматериалов. Установлены пути повышения их эксплуатационных характеристик. Определены оптимальные составы и условия синтеза блочных вспененных материалов, которые можно рекомендовать для использования в качестве теплоизоляционных и конструкционно-теплоизоляционных при строительстве и реконструкции гражданских и промышленных зданий.

Работа выполнена в рамках темы НИР №0226-2019-0068 и частично поддержана из средств гранта РФФИ (17-43-510364 p_a).

\section{Литература}

1. Дамдинова Д.Р., Хардаев П.К., Павлов В.Е., Дружинин Д.К., Вторушин Н.С., Баторова И.Ю. Золошлаковые отходы теплоэнергетики как сырье для получения пеностекол // Вестник ВСГУТУ. 2016. №2 (59). С. 9-14.

2. Кетов П.А. Получение строительных материалов из гидратированных полисиликатов // Строительные материалы. 2012. №11. С. 22-24.

3. Кутугин В.А., Лотов В.А., Ревенко В.В. Пеностекло на основе природного и техногенного аморфного кремнезема // Техника и технология силикатов. 2016. №3. С. 24-28.

4. Манакова Н.К., Суворова О.В. Теплоизоляционный материал на основе кремнеземсодержащих отходов переработки рудного сырья Кольского полуострова // Журнал прикладной химии. 2012. Т. 85 . №11. C. $1741-1745$.

5. Манакова Н.К., Суворова О.В. Теплоизоляционные материалы на основе кремнеземсодержащего сырья // Труды Кольского научного центра РАН. 2015. № 31. С. 562-564.

6. Манакова Н.К., Суворова О.В. Горнопромышленные отходы Мурманской области для получения блочных пеносиликатов // Труды Ферсмановской научной сессии ГИ КНЦ РАН. 2017. №14. С. $243-245$.

7. Мелконян Р.Г., Макаров Д.В., Суворова О.В. Экологические проблемы использования техногенного сырья в производстве стекла и керамики. Апатиты: Изд-во Кольского научного центра РАН. 2016. 224 с.

8. Мелконян Р.Г., Суворова О.В., Макаров Д.В., Манакова Н.К. Использование горных пород и промышленных отходов для производства стеклообразных пеноматериалов // Горный информационно-аналитический бюллетень. 2018. № S1. С. 350-368.

9. Смолий В.А., Косарев А.С., Яценко Е.А. Ячеистые теплоизоляционные строительные стекломатериалы на основе отходов тепловых электростанций и черной металлургии // Стекло и керамика. 2017. №2. С. 20 -22.

10. Суворова О.В., Манакова Н.К. Использование отходов и побочных продуктов переработки апатитонефелиновых и эвдиалитовых руд для получения теплоизоляционных пеностеклокристаллических материалов // Вестник Мурманского государственного технического университета. 2017. Т. 20. №1/2. С. $189-196$.

11. Яценко Е.А., Зубехин А.П., Смолий В.А., Грушко И.С., Косарев А.С., Гольцман Б.М. Ресурсосберегающая технология теплоизоляционно-декоративного стеклокомпозиционного материала на основе золошлаковых отходов // Стекло и керамика. 2015. № 6. С. 34-38. 